\title{
Study of Virulence Markers and Antifungal Susceptibility by Vitek-2 in Various Candida Species Isolated from Cases of Vulvovaginal Candidiasis
}

\author{
Rafat Siddiqi $^{1}$, D.K. Mendiratta1, Atul Rukadikar ${ }^{1 *}$ and Sandhya Gadre ${ }^{2}$ \\ ${ }^{1}$ Department of Microbiology, Chirayu Medical College and Hospital, Bhopal, India \\ ${ }^{2}$ Department of Obstetrics \& Gynaecology, Chirayu Medical College and Hospital, Bhopal, India \\ *Corresponding author
}

\section{A B S T R A C T}

Vulvovaginal candidiasis (VVC) is the most common cause of vaginitis accounting for 17 to $39 \%$ of symptomatic women. Both Candida albicans and non albicans Candida species are involved in VVC. Amongst various virulence factors proposed for Candida, Biofilm formation, Proteinase and Extracellular Phospholipases are usually implicated in its pathogenicity. Concern is also rising with respect to antifungal resistance in both Candida

\section{Keywords}

Candida species, Virulence markers, Antifungal susceptibility testing.

\section{Article Info}

Accepted: 26 October 2017 Available Online: 10 December 2017 albicans and non albicans Candida. Present study is carried out to study virulence function and antifungal susceptibility by Vitek $2 \mathrm{C}$ in isolates recovered from women in reproductive age group with signs and symptoms of VVC. Three vaginal swabs from 168 women of reproductive age with vulvovaginal candidiasis were collected. Direct microscopy and Gram's stained smear were examined for presence of budding yeast cells and pseudohyphae followed by isolation and identification of Candida species by conventional methods. The virulence factors studied were phospholipase, biofilm formation and proteinase. Antifungal susceptibility testing was carried out by VITEK 2C (Biomerieux). Vaginal swab of $55(32.7 \%)$ subjects showed pure growth of Candida species. The most common species isolated was $C$. albicans $(34.6 \%)$ followed by $C$. tropicalis $(23.6 \%)$ and $C$. glabrata $(21.8 \%)$. The production of virulence factor phospholipase was shown by most strains $(83.6 \%)$ followed by biofilm formation $(74.5 \%)$ and proteinase production (70.9\%). MIC by VITEK-2 showed highest resistance to fluconazole (16.4\%), followed by that to voriconazole (10.9\%) and amphotericin B $(5.4 \%)$. The study duly emphasizes the need for the determination of virulence factors and antifungal susceptibility testing for effective and prompt determination of not only the pathogenic state of candida species but also proper management of the VVC cases.

\section{Introduction}

VVC is defined as a condition with signs and symptoms of inflammation in the presence of Candida species and in absence of other etiology. ${ }^{1}$ Women having VVC present with spectrum of manifestations ranging from asymptomatic colonization to severe acute symptomatic infection. VVC accounts for 17$39 \%$ of all cases of vaginitis among symptomatic women. Recent studies suggest that there is an increasing incidence of isolation of non albicans species from cases of VVC besides C.albicans. ${ }^{2}$

The transition of candida sp. from commensal to potential pathogen is determined by various host predisposing factors and virulence 
attributes of infecting species such as adherence to host tissue and medical devices, biofilm formation and secretion of extracellular enzymes like phospholipases and proteinases $^{3}$. Identifying these virulence factors in infecting pathogens and understanding their effects on human host is a major challenge. ${ }^{4}$

Concern is also rising about the emergence of antifungal resistance in Candida. Although amphotericin B and flucytosine continue to be more effective, resistance to azole group of antifungal agents, which are safe and effective, is of concern. Most non albicans Candida species have higher minimum inhibitory concentrations to the azole antifungal agents and infections they cause are often difficult to treat. ${ }^{3}$ Any information on distribution and etiology of Candida is always very useful for epidemiological purpose. In view of the above, the present study has been undertaken with the following objectives.

The present study was undertaken with the following aim and objectives.

To demonstrate the following virulence markers in the candida species isolated:

-Phospholipase production

-In vitro biofilm / slime layer formation

-Proteinase production

To determine the Minimum Inhibitory Concentration (MIC) of Candida species using Vitek-2C system (Biomerieux).

\section{Materials and Methods}

Three high vaginal swabs were collected from168 women of reproductive age group attending Obstetrics and Gynecology (OBGY) department of tertiary care hospital of central India between January 01, 2016 and
June 30, 2017 for the present study. The study was approved by institutional ethics committee. Patients fulfilling the defining criteria of vaginitis i.e. those with vaginal discharge, irritation, itching with or without pain in reproductive age group were included in the study.

A detailed clinical examination was done and documented. Two vaginal swabs were subjected to $\mathrm{KOH}$ wet mount microscopy and Gram's stain for presence of budding yeast and pseudohyphae. Subsequently, third swab was inoculated on SDA for yeast isolation. Growth of Candida was confirmed by colony morphology, Gram's stain and speciated by its characteristics on CHROME agar (Himedia Mumbai), sugar assimilation and fermentation tests. ${ }^{4}$

The virulence factors studied were biofilm formation, and production of phospholipase, and proteinase.

\section{Detection of virulence markers}

\section{Phospholipase detection ${ }^{5}$}

All isolates were screened for their extracellular phospholipase activity by the following procedure: Egg yolk medium consisting of $13.0 \mathrm{~g}$ Sabouraud's dextrose agar (SDA), 11.7g NaCl, $0.111 \mathrm{~g} \mathrm{CaCl}_{2}$, and $10 \%$ sterile egg yolk was used. The egg yolk was centrifuged at $5000 \mathrm{~g}$ for $30 \mathrm{~min}$ at room temperature, and $20 \mathrm{ml}$ of the supernatant was added to the sterilized medium. Extracellular phospholipase activity was detected by inoculating $10 \mu \mathrm{l}$ aliquots of the yeast suspension (approximately $10^{8}$ yeast cells $/ \mathrm{ml}$ ) into the wells punched onto the surface of the egg yolk medium. The diameter of the precipitation zone around the well was measured after incubation at $37^{\circ} \mathrm{C}$ for $48 \mathrm{~h}$. The phospholipase index $(\mathrm{Pz})$ was defined as the ratio of the diameter of the growth to the 
total diameter of the growth plus the precipitation zone. $\mathrm{Pz} \geq 1$ indicated no phospholipase activity. $\mathrm{Pz}<1$ indicated positive phospholipase activity. C. albicans ATCC 10231 was used as positive control.

\section{Proteinase detection $^{5}$}

Candidaproteinase was detected by modified Staib method. Proteinase activity was measured in terms of Bovine Serum Albumin (BSA) degradation. Bovine serum albumin medium (dextrose 2\%, $\mathrm{KH}_{2} \quad \mathrm{PO}_{4} \quad 0.1 \%$, $\mathrm{MgSO}_{4} 0.05 \%$, agar $2 \%$ was mixed after cooling to $50^{\circ} \mathrm{C}$ with $1 \%$ bovine serum albumin solution) was used. Proteinase activity was detected by inoculating $10 \mu \mathrm{l}$ aliquots of the yeast suspension (approximately $10^{8}$ yeast cells $/ \mathrm{ml}$ ) into the wells punched onto the surface of the medium. The plates were incubated at $37^{\circ} \mathrm{C}$ for 2 days. After incubation, the plates were fixed with $20 \%$ trichloroacetic acid and stained with $1.25 \%$ amidoblack. Decolourisation was performed with $15 \%$ acetic acid. Opaqueness of the agar, corresponding to a zone of proteolysis around the wells that were not stained with amidoblack indicated degradation of the protein. The diameter of unstained zones around the well was considered as a measure of proteinase production. The proteinase index $(\mathrm{Pz})$ was measured in terms of the ratio of the diameter of the growth of the unstained zone. $\mathrm{Pz} \geq 1$ - no proteinase activity detected in the strain while $\mathrm{Pz}<1$ - positive for proteinase production. $C$. albicans ATCC 10231 was used as positive control.

\section{In vitro biofilm formation/slime production $^{6}$}

Biofilm production was determined by visual methods. Colonies from the surface of SDA plate were inoculated into a polystyrene tube (Falcon conical tube with screw cap) containing $10 \mathrm{ml}$ of Sabouraud-dextrose broth (SDB) supplemented with glucose (final concentration $8 \%$ ). After incubation at $35^{\circ} \mathrm{C}$ for $48 \mathrm{~h}$, the broth in the tubes was gently aspirated. The tubes were washed with distilled water twice and then stained with $2 \%$ safranin for $10 \mathrm{~min}$. They were then examined for the presence of an adherent layer. Biofilm production was scored as negative $(-)$, weak $(+)$, moderate $(++)$ or strong $(+++)$. The biofilm producer Staphylococcus epidermidis ATCC 35984 was used as a positive control.

\section{Antifungal susceptibility testing}

\section{MIC determination by VITEK $2^{7}$}

Minimum Inhibitory Concentration (MIC) is the lowest drug concentration that prevents visible microorganism growth after overnight incubation.AST-YS01 card of Vitek 2 system was used for susceptibility testing of amphotericin B (AmB), fluconazole (FLC) and voriconazole (VRC). MIC of the antifungals was determined as described in the company's manual.

\section{Results and Discussion}

Among the 168 subjects included in the study, vaginal swab of $55(32.7 \%)$ subjects showed pure growth of Candida species. The most common species isolated was $C$. albicans (34.6\%) followed by $C$. tropicalis $(23.6 \%)$ and C. glabrata (21.8\%) (Table 1). All the 55 isolates recovered showed the presence of one or more of the three virulence factors (phospholipase, biofilm formation and proteinase production) studied. The production of virulence factor phospholipase was shown by most strains $(83.6 \%)$ followed by biofilm formation (74.5\%) and proteinase production (70.9\%). Among C. albicans, most strains produced phospholipase (94.7\%), followed by biofilm formation $(89.5 \%)$ and proteinase production $(84.2 \%)$. Among the 
$N A C$ isolates, just as C. albicans, most produced phospholipase $(77.8 \%)$, followed by biofilm production $(66.7 \%)$ and proteinase production (63.9\%). Among the biofilm formers $C$. albicans (41.5\%) showed the maximum positivity, followed by $C$. glabrata (22.0\%), C. tropicalis (19.5\%) and other species. Among proteinase producers again $C$. albicans $(41.0 \%)$ showed maximum positivity, but it was followed by $C$. tropicalis (17.9\%), C. glabrata (17.9\%), and other species. Among phospholipase producers, though again $C$. albicans $(39.1 \%)$ showed maximum positivity, it was followed by $C$. glabrata $(23.9 \%)$, C. tropicalis $(21.7 \%)$ and other species (Table 2).

As per MIC results determined by Vitek 2C (Biomerieux) highest resistance was seen to fluconazole $(16.4 \%)$, followed by that to voriconazole $(10.9 \%)$ and amphotericin B $(5.4 \%)$. Higher resistance seen to fluconazole as compared to others was statistically not significant (p-value: 0.56).In case of C.albicans, resistance to amphotericin B, fluconazole and voriconazole was $10.5 \%$, $31.6 \%$ and $21.1 \%$ respectively. The only isolate of $C$. krusei showed resistance to fluconazole only $(100 \%)$, Resistance in $C$. parapsilosis was to the tune of $50 \%$ to all the three antifungals tested. MIC of $C$. tropicalis strains suggested resistance to fluconazole $(7.7 \%)$ and voriconazole $(7.7 \%)$ (Table 3$)$.

As shown in Table 4, 18.2\% of our isolates were resistant. Among these, $40 \%$ were resistant to single drug and $60 \%$ were multi drug resistant (40\% to the two azoles and $20 \%$ to all the three antifungals). With respect to individual species, $36.8 \%$ of $C$. albicans, $100 \%$ C. krusei, $50 \%$ of C. parapsilosis and $7.7 \%$ of $C$. tropicalis showed resistance to one or more antifungal tested. Among the resistant $C$. albicans strains, $42.9 \%$ showed resistance to one of the three antifungals, $42.9 \%$ to two antifungals (fluconazole and voriconazole) while $14.2 \%$ showed resistance to all the three antifungals tested (amphotericin B, fluconazole, voriconazole). In case of $C$. parapsilosis $50 \%$ strains were resistant, and 1 strain showed resistance to all the three antifungals tested. The only isolate of $C$. krusei recovered in the present study was resistant to a single drug, fluconazole (100\%). Of the 13 isolates of C. tropicalis, 1 $(7.7 \%)$ isolate was resistant and this was resistant to both the azoles tested.

In the present study $C$. albicans was the commonest species isolated $(11.3 \%$ among the study subjects and $34.6 \%$ among isolates). Earlier report from Egypt $(86.6 \%)^{8}$, Kuwait $(73.9 \%){ }^{9}$ Yemen $(65.9 \%)^{10}$ and Saudi Arabia $(59 \%)^{11}$ have also reported higher rate of isolation of $C$. albicans in cases of VVC. Worldwide, rates of the isolation of $C$. albicans in cases of VVC ranges between $47 \%$ and $89 \%$ in studies from Nicaragua ${ }^{12}$, Australia $^{13,14}$, Turkey $^{15}, \operatorname{Iran}^{16}$, Nigeria ${ }^{17,18}$ and India ${ }^{19}$.

In our study the rate of isolation of $N A C$ was higher $(21.4 \%)$ among study subjects and $65.4 \%$ among the isolates), than that of $C$. albicans $(11.3 \%$ among the study subjects and $34.6 \%$ among isolates). Higher isolation of $N A C$ over $C$. albicans has also been reported by Kikani et al., ${ }^{426}$ (55.6\% vs. $\left.44.4 \%\right)$, Deepa Babin et al., ${ }^{19}(64.5 \%$ vs. $35.5 \%)$ and Namrata et al., ${ }^{20}(53 \%$ vs. $47 \%)$.

However, there have been reports of higher isolation of the commonest species, $C$. albicans over NAC from Tehran ${ }^{21}(65.1 \%$ vs. $34.9 \%)$, Sudan 22 (92 \% vs. 8\%), Egypt ${ }^{23}$ $(60.3 \%$ vs. $39.7 \%)$, Turkey $^{24}(59.9 \%$ vs $40.1 \%)$ and $\operatorname{India}^{25}$ (66\% vs. $\left.34 \%\right)$.

In the present study, C. tropicalis $(23.6 \%)$ was the second most commonest isolate after C. albicans. Deepa Babin et al., ${ }^{19}$ (29.4\%) and Namrata Kalia et al., ${ }^{20}$ (24.1\%) from 
India have also reported similar findings. Studies have reported the rates of $C$. tropicalis isolation in cases $\mathrm{VVC}$ ranging between $4 \%$ and $26.4 \% .^{9,12,19}$

However, C. glabratahas been reported to be the second most common isolate in cases of VVC from Saudi Arabia ${ }^{11}$ (31\%), Turkey $^{15}$ (34.5\%), Australia ${ }^{14}$ (20\%), Egypt $^{8}$ (12.7\%) and India $^{19}(11 \%)$. In the present study C. glabrata $(21.8 \%)$ was the third commonest isolate after $C$. albicans and $C$. tropicalis. Other species isolated in the present study were $C$. dubliniensis $(7.3 \%), C$. lusitaniae (5.5\%), C. parapsilosis (3.6\%), C. guilliermondii (1.8\%) and C. krusei (1.8\%). Rates of isolation of $C$. dubliniensi shave been reported to range between $0.17 \%$ to $29.5 \%$, while that of $C$. krusei from $3 \%$ to $15.7 \%$. $^{11,12,15,19}$

Cultural, ethnic and epidemiological differences may influence the isolation rate of different yeast from vulvovaginitis samples. However, it goes beyond doubt that there is need to speciate Candida, be it for epidemiological purpose or from point of view of ensuring institution of the correct antifungal.

\section{Virulence markers}

All pathogenic microorganisms have developed mechanisms that allow successful colonization or infection of the host. As a result, most pathogens, including Candida species, have developed an effective battery of putative virulence factors and specific strategies to assist in their ability to colonize host tissues, cause disease, and overcome host defenses. The virulence factors expressed or required by Candida species, and in particular C. albicans, to cause infections may well vary depending on the type of infection (i.e. mucosal or systemic), the site and stage of infection, and the nature of the host response. It seems apparent that a panel of virulence attributes is involved in the infective process, but no single factor accounts for Candida virulence and not all expressed virulence attributes may be necessary for a particular stage of infection. In present study all the 55 isolates recovered showed the presence of one or more of the three virulence factors (biofilm formation, proteinase and phospholipase production) studied. The presence of each of these virulence factors was seen more among C. albicans as compared to non albicans Candida (Table 2).

It has been reported in several studies that aspartic proteinases are produced at higher rates by $C$. albicans, as compared to $N A C$. In our study too, production of proteinase was seen more among $C$. albicans (84.2\%) as compared to NAC (63.9\%). Koga-ito et al., ${ }^{26}$ showed higher proteinase production among the $C$. albicans strains isolated from oral candidiasis patients when compared to those isolated from control individuals. Costa et al., ${ }^{27}$ found that $88.1 \%$ of Candida albicansand $69.8 \%$ of non-albicans Candida isolates produced proteinase. Vinitha et al., ${ }^{5}$ detected proteinase activity in $74.5 \%$ of Candida species isolated from the blood samples. The proteinase-producing capacity of Candida nonalbicans $(50.4 \%)$ was less than that of $C$. albicans $(67.3 \%)$. Somansu Basu et al., ${ }^{28}$ also reported that $C$. albicans from various clinical sources, exhibited strong proteinase $(66.6 \%)$. Vivek et al., ${ }^{29}$ reported proteinase activity in $61.4 \%$ of their isolates, and observed maximum proteinase activity in $C$. albicans isolates followed by that in $C$. glabrata, $C$. kruse $i$ and $C$. tropicalis. They are of the opinion that the secreted proteinases are responsible for the adhesion and tissue invasion. 
Table.1 Candida species isolated by conventional techniques

\begin{tabular}{|c|c|}
\hline Candida species & Total n [\%] \\
\hline C. albicans & $19[34.6]$ \\
\hline C. tropicalis & $13[23.6]$ \\
\hline C. glabrata & $12[21.8]$ \\
\hline C. dublinensis & $04[7.3]$ \\
\hline C. lusitaniae & $03[5.5]$ \\
\hline C. parapsilosis & $02[3.6]$ \\
\hline C. guilliermondi & $01[1.8]$ \\
\hline C. krusei & $01[1.8]$ \\
\hline Total & $\mathbf{5 5}$ \\
\hline
\end{tabular}

[ ] - Figures in parenthesis are percentages from vertical total

Table.2 Candida species-wise distribution of virulence factors

\begin{tabular}{|c|c|c|c|}
\hline Candida spp & $\begin{array}{c}\text { Biofilm } \\
\text { formation } \\
\mathbf{n}[\%]\end{array}$ & $\begin{array}{c}\text { Proteinase } \\
\text { production } \\
\text { n[\%] }\end{array}$ & $\begin{array}{c}\text { Phospholipase } \\
\text { production } \\
\mathbf{n}[\%]\end{array}$ \\
\hline C. albicans $(n=19)$ & $17[41.5]$ & $16[41.0]$ & $18[39.1]$ \\
\hline $\begin{array}{l}\text { C. glabrata } \\
(n=12)\end{array}$ & $09[22.0]$ & $07[17.9]$ & $11[23.9]$ \\
\hline $\begin{array}{l}\text { C. tropicalis } \\
\qquad(n=13)\end{array}$ & $08[19.5]$ & $07[17.9]$ & $10[21.7]$ \\
\hline $\begin{array}{l}\text { C. dubliniensis } \\
(n=04)\end{array}$ & $03[7.3]$ & $04[10.3]$ & $04[8.7]$ \\
\hline $\begin{array}{l}\text { C. parapsilosis } \\
(n=02)\end{array}$ & $02[4.9]$ & $00[0.0]$ & $01[2.2]$ \\
\hline $\begin{array}{l}\text { C. Iusitaniae } \\
(n=03)\end{array}$ & $01[2.4]$ & $03[7.7]$ & $01[2.2]$ \\
\hline $\begin{array}{c}\text { C. krusei } \\
(n=01)\end{array}$ & $01[2.4]$ & $01[2.6]$ & $00[0.0]$ \\
\hline $\begin{array}{l}\text { C. guilliermondii } \\
(n=01)\end{array}$ & $00[0.0]$ & $01[2.6]$ & $01[2.2]$ \\
\hline Total & 41 & 39 & 46 \\
\hline
\end{tabular}

[]: Figures in parenthesis are percentages from vertical total 
Table.3 MIC $(\mu \mathrm{g} / \mathrm{ml})$ results in different Candida species by Vitek 2

\begin{tabular}{|c|c|c|c|c|c|c|c|c|c|}
\hline & \multicolumn{3}{|c|}{ Amphotericin-B } & \multicolumn{3}{|c|}{ Fluconazole } & \multicolumn{3}{|c|}{ Voriconazole } \\
\hline $\begin{array}{l}\text { Candida species } \\
\text { (n) }\end{array}$ & $\begin{array}{c}S \\
\leq 1\end{array}$ & $\begin{array}{l}\text { I } \\
2\end{array}$ & $\begin{array}{l}R \\
\geq 4\end{array}$ & $\begin{array}{c}S \\
\leq 2 * / \\
\leq 8^{* *}\end{array}$ & $\begin{array}{c}I \\
* / \\
16- \\
32 * *\end{array}$ & $\begin{array}{c}\mathbf{R} \\
\geq \mathbf{8} * / \\
\geq \mathbf{6 4}\end{array}$ & $\begin{array}{c}\mathrm{S} \\
\leq 0.125 * / \\
\leq 0.5 * * / \\
1 * * *\end{array}$ & $\begin{array}{c}\text { I } \\
\mathbf{0 . 2 5 - 0 . 5} * / \\
1 * * / \\
2 * * *\end{array}$ & $\begin{array}{c}\mathbf{R} \\
\geq 1 * / \\
\geq 2 * * 1 \\
\geq 4 * * *\end{array}$ \\
\hline $\begin{array}{l}\text { C. albicans } \\
\text { (19) }\end{array}$ & $\begin{array}{c}15 \\
(79.0)\end{array}$ & $\begin{array}{c}2 \\
(10.5)\end{array}$ & $\begin{array}{c}2 \\
(\mathbf{1 0 . 5})\end{array}$ & $\begin{array}{c}11 \\
(57.9)\end{array}$ & $\begin{array}{c}2 \\
(10.5)\end{array}$ & $\begin{array}{c}6 \\
(\mathbf{3 1 . 6})\end{array}$ & $\begin{array}{c}15 \\
(79.0)\end{array}$ & $\begin{array}{c}0 \\
(0.0)\end{array}$ & $\begin{array}{c}4 \\
(\mathbf{2 1 . 1})\end{array}$ \\
\hline $\begin{array}{l}\text { C. dubliniensis } \\
\text { (4) }\end{array}$ & $\begin{array}{c}4 \\
(100)\end{array}$ & $\begin{array}{c}0 \\
(0.0)\end{array}$ & $\begin{array}{c}0 \\
(0.0)\end{array}$ & $\begin{array}{c}4 \\
(100.0)\end{array}$ & $\begin{array}{c}0 \\
(0.0)\end{array}$ & $\begin{array}{c}0 \\
(0.0)\end{array}$ & $\begin{array}{c}4 \\
(100.0)\end{array}$ & $\begin{array}{c}0 \\
(0.0)\end{array}$ & $\begin{array}{c}0 \\
(0.0)\end{array}$ \\
\hline $\begin{array}{c}\text { C. glabrata } \\
\text { (12) }\end{array}$ & $\begin{array}{c}12 \\
(100) \\
\end{array}$ & $\begin{array}{c}0 \\
(0.0) \\
\end{array}$ & $\begin{array}{c}0 \\
(0.0)\end{array}$ & $\begin{array}{c}11 \\
(91.6)\end{array}$ & $\begin{array}{c}1 \\
(8.4)\end{array}$ & $\begin{array}{c}0 \\
(0.0)\end{array}$ & $\begin{array}{c}12 \\
(100.0)\end{array}$ & $\begin{array}{c}0 \\
(0.0)\end{array}$ & $\begin{array}{c}0 \\
(0.0)\end{array}$ \\
\hline $\begin{array}{l}\text { C. guilliermondii } \\
\text { (1) }\end{array}$ & $\begin{array}{c}1 \\
(100)\end{array}$ & $\begin{array}{c}0 \\
(0.0)\end{array}$ & $\begin{array}{c}0 \\
(0.0)\end{array}$ & $\begin{array}{c}1 \\
(100.0)\end{array}$ & $\begin{array}{c}0 \\
(0.0)\end{array}$ & $\begin{array}{c}0 \\
(0.0)\end{array}$ & $\begin{array}{c}1 \\
(100.0)\end{array}$ & $\begin{array}{c}0 \\
(0.0)\end{array}$ & $\begin{array}{c}0 \\
(0.0)\end{array}$ \\
\hline $\begin{array}{l}\text { C. krusei } \\
\text { (1) }\end{array}$ & $\begin{array}{c}0 \\
(0.0)\end{array}$ & $\begin{array}{c}1 \\
(100)\end{array}$ & $\begin{array}{c}0 \\
(0.0)\end{array}$ & $\begin{array}{c}0 \\
(0.0)\end{array}$ & $\begin{array}{c}0 \\
(0.0)\end{array}$ & $\begin{array}{c}1 \\
(\mathbf{1 0 0 . 0})\end{array}$ & $\begin{array}{c}1 \\
(100.0)\end{array}$ & $\begin{array}{c}0 \\
(0.0)\end{array}$ & $\begin{array}{c}0 \\
(0.0)\end{array}$ \\
\hline $\begin{array}{l}\text { C. lusitaniae } \\
\text { (3) }\end{array}$ & $\begin{array}{c}3 \\
(100)\end{array}$ & $\begin{array}{c}0 \\
(0.0)\end{array}$ & $\begin{array}{c}0 \\
(0.0)\end{array}$ & $\begin{array}{c}3 \\
(100.0)\end{array}$ & $\begin{array}{c}0 \\
(0.0)\end{array}$ & $\begin{array}{c}0 \\
(0.0)\end{array}$ & $\begin{array}{c}3 \\
(100.0)\end{array}$ & $\begin{array}{c}0 \\
(0.0)\end{array}$ & $\begin{array}{c}0 \\
(0.0)\end{array}$ \\
\hline $\begin{array}{c}\text { C. parapsilosis } \\
\text { (2) }\end{array}$ & $\begin{array}{c}1 \\
(50.0)\end{array}$ & $\begin{array}{c}0 \\
(0.0)\end{array}$ & $\begin{array}{c}1 \\
(\mathbf{5 0 . 0})\end{array}$ & $\begin{array}{c}1 \\
(50.0)\end{array}$ & $\begin{array}{c}0 \\
(0.0)\end{array}$ & $\begin{array}{c}1 \\
(\mathbf{5 0 . 0})\end{array}$ & $\begin{array}{c}1 \\
(50.0)\end{array}$ & $\begin{array}{c}0 \\
(0.0)\end{array}$ & $\begin{array}{c}1 \\
(\mathbf{5 0 . 0})\end{array}$ \\
\hline $\begin{array}{c}\text { C. tropicalis } \\
(13)\end{array}$ & $\begin{array}{c}13 \\
(100)\end{array}$ & $\begin{array}{c}0 \\
(0.0) \\
\end{array}$ & $\begin{array}{c}0 \\
(0.0) \\
\end{array}$ & $\begin{array}{c}11 \\
(84.6) \\
\end{array}$ & $\begin{array}{c}1 \\
(7.7) \\
\end{array}$ & $\begin{array}{c}1 \\
(7.7)\end{array}$ & $\begin{array}{c}12 \\
(92.3) \\
\end{array}$ & $\begin{array}{c}0 \\
(0.0)\end{array}$ & $\begin{array}{c}1 \\
(7.7) \\
\end{array}$ \\
\hline Total (55) & $\begin{array}{c}49 \\
(89.0)\end{array}$ & $\begin{array}{c}3 \\
(5.5)\end{array}$ & $\begin{array}{c}3 \\
(5.5)\end{array}$ & $\begin{array}{c}42 \\
(76.4)\end{array}$ & $\begin{array}{c}4 \\
(7.2)\end{array}$ & $\begin{array}{c}9 \\
\text { (16.4) }\end{array}$ & $\begin{array}{c}49 \\
(89.1)\end{array}$ & $\begin{array}{c}0 \\
(0.0)\end{array}$ & $\begin{array}{c}6 \\
6 \\
(\mathbf{1 0 . 9})\end{array}$ \\
\hline
\end{tabular}

$\mathrm{S}$ - Sensitive, I - Intermediate, R - Resistant

Interpretive criteria of Fluconazole / Voriconazole for:

*-C. albicans / C. parapsilosis, ${ }^{* * C}$. krusei, ${ }^{* * *}$ other Candida spp.

Table.4 Multidrug resistance among resistant isolates

\begin{tabular}{|c|c|c|c|c|}
\hline & $\begin{array}{c}\text { No. } \\
\text { resistant } \\
(\%)\end{array}$ & $\begin{array}{c}\text { R to } \\
\text { single } \\
\text { drug }\end{array}$ & \multicolumn{2}{|c|}{ Multidrug resistance pattern } \\
\hline Candida species $(\mathbf{n})$ & & & $\mathbf{F + V}$ & $\mathbf{A + F}+\mathbf{V}$ \\
\hline C. albicans $(\mathrm{n}=19)$ & $7(36.8)$ & $3[42.9]$ & $3[42.9]$ & $1[14.2]$ \\
\hline C. krusei $(\mathrm{n}=1)$ & $1(100)$ & $1[100]$ & 0 & 0 \\
\hline C. parapsilosis $(\mathrm{n}=2)$ & $1(50.0)$ & 0 & 0 & $1[100.0]$ \\
\hline C. tropicali $(\mathrm{n}=13)$ & $1(7.7)$ & 0 & $1[100]$ & 0 \\
\hline Total $(\mathrm{n}=55)$ & $10(18.2)$ & $4(7.3)$ & $4(7.3)$ & $2(3.6)$ \\
& {$[40.0]$} & {$[40.0]$} & {$[20.0]$} \\
\hline
\end{tabular}

Note: None of the strains showed resistance to $\mathrm{A}+\mathrm{F}$ and $\mathrm{A}+\mathrm{V}$

$\mathrm{R}$ - Resistant, A-Amphotericin B, F-Fluconazole, V-Voriconazole

() Figures in parenthesis are percentages from ' $n$ '

[] Figures in parenthesis are from numbers mentioned in column "No. resistant" of respective species 
Among the $N A C$ isolates in the present study maximum proteinase positivity was seen in $C$. tropicalis $(17.9 \%)$, C. glabarata $(17.9 \%)$ and other species. Suzane Katy et al., ${ }^{30}$ reported proteinase activity in $33.3 \%$ C. tropicalis and in $20 \%$ C. glabrata, followed by that in $15.3 \%$ C. parapsilopsis, recovered from vaginal secretions. Our results are similar to this study especially with respect to $C$. glabrata. However, none of our $C$. parapsilosis isolates produced proteinase. Candido et al., ${ }^{31}$ have opined that NAC species do not secrete proteinase.

Phospholipases act as a virulence factor by degrading cell membranes. In this study, the phospholipase activity was more associated with $C$. albicans $(94.7 \%)$ as compared to $N A C$ $\left(77.8 \%\right.$ ) (Table 2). Costa et al., ${ }^{27}$ reported phospholipase production in $55.9 \%$ C. albicans isolates, and only in $37.7 \%$ non-albicans Candida. In another study conducted by Samaranayake et al., ${ }^{32} 80 \%$ isolates of $C$. albicans recovered from HIV patients were phospholipase-positive. In the study of Somansu Basu et al., ${ }^{29}, 48.7 \%$ clinical isolates of $C$. albicans demonstrated phospholipase activity. Vinitha et al., ${ }^{5}$ reported that phospholipase activity was detected in $44.14 \%$ isolates, which included $46.93 \%$ of $C$. albicans and $42 \%$ NAC. Suzane Katy et al., ${ }^{30}$ demonstrated phospholipase activity in $8.9 \%$ isolates from vaginal secretions and maximum production was seen in C. albicans $(42.8 \%)$ isolates. Vinita et al., ${ }^{5}$ in their study have shown that even though all the isolated strains were pathogenic, not all produced phospholipase as virulent factor, and have suggested that the virulence of Candida species is attributed not to a single factor but to a combination of several factors, like proteinase, phospholipase, biofilm production etc. Fule et al., ${ }^{33}$ reported phospholipase activity in $81.1 \%$ of all their vaginal isolates studied. They could not demonstrate any phospholipase activity in $N A C$.
Mahmoudabadi et al., ${ }^{34}$, reported that all clinical isolates of $C$. albicans from VVC showed phospholipase activity while Basu et $a l .{ }^{28}$, reported this enzyme activity in $66.6 \%$ of vaginal isolates.

In present study among the $N A C$ species $C$. glabarata $(23.9 \%)$ and C. tropicalis $(21.7 \%)$ showed maximum phospholipase production. Suzane Katy et al., ${ }^{33}$ reported phospholipase activity in $6.6 \%$ C. glabrata, while none in $C$. tropicalis and $C$. krusei. Sachin et al., ${ }^{35}$ reported high phospholipase activity in $C$. tropicalis $(57.2 \%)$.

Borst and Fluit ${ }^{36}$ believe that phospholipase activity could be associated with strain characteristics, geographical region and infection type, which probably justifies the difference in prevalence of this activity, observed in different studies.

The formation of Candida biofilms carries important clinical repercussions because of the ability of cells within biofilms to withstand host immune defenses. Candida biofilms adversely impact the health of the patients with increasing frequency and severity and with soaring economic sequelae. However, Thamke et al., ${ }^{37}$ did not find any significant difference in ability of biofilm formation by $C$. albicans isolated from cases of VVC $(40 \%)$ and those from asymptomatic women $(27.27 \%)$.

Different strains of $C$. albicans and different Candida species differ in their capacities to form biofilms ${ }^{38}$. In the present study, $41(74.5 \%)$ Candida isolates showed biofilm production, and biofilm formation by $C$. albicans $(89.5 \%)$ was higher than NAC (66.7\%). Yigit et al., ${ }^{6}$ reported higher positivity in $C$. albicans $(88.2 \%)$ strains as compared to $N A C(51.6 \%)$ as did Ilknur Dag et al., ${ }^{39}(C$. albicans vs NAC: $39.3 \%$ vs $37.79 \%$ ). However, Tumbarello et al., 
reported that biofilm production by $C$. albicans was significantly lower $(22.6 \%)$ than that by all other non-C. albicans species $(33.3 \%)$. Among biofilm producers, the NAC species producing biofilm in our study after C. albicans (41.5\%) were C. glabrata $(22 \%)$ and $C$. tropicalis (19.5\%)., Tumbarello et al., ${ }^{40}$ reported biofilm formation in $30 \%$ of $C$. tropicalis and in $21 \%$ of C. parapsilosis.

Thorough search of literature revealed that there are few studies on simultaneous detection of different virulence factors. Our study revealed that of the 55 isolates that produced one or the other virulence factors, $44(80 \%)$ produced two or more. In fact 27 $(49.1 \%)$ produced all the three. Among combination, biofilm together with phospholipase was commonest (14.5\%). Out of all, in $C$. albicans the commonest combined virulence factor activity seen was proteinase and phospholipase (16.7\%). Among NAC, it was biofilm and phospholipase (87.5\%).

In the study of D'Eca Junior A et al., ${ }^{41}, 29.3 \%$ of the isolates produced both phospholipases and proteinases. Kantarcioglu and Yucel et $a l .,{ }^{42}$ observed that 56 out of 60 strains of $C$. albicans and 2 out of 4 strains of $C$. kefyr tested produced both phospholipases and proteinases. A study conducted by Shimizu et al., ${ }^{43}$ investigated the ability of different Candida species to simultaneously produce hyaluronidase, chondroitin sulfatase, protease and phospholipase in order to evaluate whether they were related to Candida pathogenicity. They determined that with the exception of the $C$. albicans strains, none of the strains produced all four enzymes simultaneously.

\section{Multidrug resistance (Table 4)}

Among the 55 isolates studied, drug resistance was seen in $18.2 \%$ isolates (10 of
55 isolates) and among these $60 \%$ (40\% to the two azoles and $20 \%$ to all the three antifungals studied) showed multidrug resistance. Various mechanisms that contribute to the development of MDR have been implicated in Candida as well as in other human fungal pathogens, and some of these include over expression of or mutations in the target enzyme of azoles, lanosterol 14 alphademethylase, and transcriptional activation of genes encoding drug efflux pump proteins belonging to ATP-binding cassette (ABC) as well as to major facilitator superfamilies (MFS) of transporters. The ABC transporters, CDR1, CDR2, and an MFS pump CaMDR1, play a key role in azole resistance as deduced from their high level of expression found in several azole-resistant clinical isolates ${ }^{44}$.

Multidrug resistance across C. albicans, $C$. glabrata, $C$. tropicalis and $C$. parapsilosis was found in $22 \%$ of the isolates studied by Razzaghi-Abyaneh et al., ${ }^{45}$. In our study this was seen in $C$. albicans, $C$. tropicalis and $C$. parapsilosis.

Consideration of the interactions between azoles and amphotericin B (AmB) has become clinically significant in recent years. Prior exposure to azole especially fluconazole has resulted in pronounced increase in resistance to subsequent exposures to $\mathrm{AmB}^{46}$. Clinical isolates of $C$. tropicalis and $C$. glabrata have been reported to be resistance to both azoles and amphotericin B. This was seen in one isolate each of $C$. albicans and $C$. parapsilosis in our study. For $C$. tropicalis, $6.3 \%$ of the isolates in one study were found resistant to azoles ${ }^{47}$. In our study the only isolate of $C$. tropicalis found resistant was so to both azoles tested. Among Candida isolates, there is a strong positive correlation between fluconazole MICs and those of itraconazole, voriconazole, posaconazole, and ravuconazole, indicating considerable crossresistance $^{48}$. Thus, resistance to fluconazole 
may serve as a surrogate marker in predicting resistance to the other extended-spectrum triazoles with Candida spp. An analysis of cross-resistance among fluconazole and the other triazoles demonstrated that isolates of Candida spp for which fluconazole MICs are $\geq 64 \mathrm{mcg} / \mathrm{mL}$ (resistant) also tend to be less susceptible (MICs $>2 \mathrm{mcg} / \mathrm{mL}$ ) to voriconazole also. In our study all our 6 multidrug resistant isolates were resistant to both fluconazole and voriconazole.

Antifungal drug resistance is particularly more serious when it develops not only against the administered drug, but also to other non-related chemical compounds. Hence, it is important to develop new methods of diagnosis, that are more rapid and efficient, and that allow not only unequivocal identification of which strain(s) are causing the infection and to which compounds they are resistant to, or at least prone to develop resistance to. An overall better understanding of the patient's clinical history and of the strain that is causing the infection is determinant to choose the most efficient therapeutic option.

The study duly emphasizes the need for the determination of virulence factors and antifungal susceptibility testing for effective and prompt determination of not only the pathogenic state of candida but also proper management of the VVC cases.

\section{References}

1. Jacqueline M. Achkar and Fries BC. Candida Infections of the Genitourinary Tract. Clin Micro Review. 2010 April; $253-273$.

2. SobelJD, Faro S, Frocs RW, Foxman B, Ledger WJ, Nyirjesy PR. Vulvovaginal candidiasis: Epidemiological, diagnostic and therapeutic considerations. Am J Obstet Gynecol., 1998; 178: 203-11.
3. Sardi JCO, Scorzoni L, Bernardi AM, Almeida F, and M.J.S. Mendes Giannini. Candida species: current epidemiology, pathology biofilm formation, natural anti-fungal products and new therapeutic options. Journal of Medical Microbiology. 2013; vol.62, no. $1,10-24$.

4. Deorukhkar S, Saini S and Mathew S. Non -albicans Candida Infection: An Emerging Threat. Interdisciplinary Perspectives on Infectious Diseases. 2014.

5. Vinitha $\mathrm{M}$ and BallalM. Proteinase and phospholipase activity as virulence factors in Candida species isolated from blood. Revlberoam Micol. 2008; 25: 208-210.

6. Yigit $\mathrm{M}$, Aktas E, Dagistan S, and Ayyildiz A. Investigating Biofilm Production, Coagulase and Hemolytic Activity in Candida Species Isolated From Denture Stomatitis Patients. Eurasian J Med. 2011 Apr; 43(1): 2732.

7. Pfaller MA, Diekema DJ, Procop GW, and Rinaldi MG. Multicenter comparison of the VITEK 2 antifungal susceptibility test with the CLSI broth microdilution reference method for testing amphotericin B, flucytosine, and voriconazole against Candida spp. J. Clin. Microbiol. 2007; 45: 3522-3528.

8. El-sayed H, Hamouda A. Candida albicans causing vulvovaginitis and their clinical response to antifungal therapy. Egypt J Med Microbiol., 2007; 16(1): 53-62.

9. Alfouzan W, Dhar R, Ashkanani H, Gupta M, Rachel C, Khan ZU. Species spectrum and antifungal susceptibility profile of vaginal isolates of Candida in Kuwait. J Mycol Med 2015; 25(1): 238.

10. Al-mamari A, Al-buryhi M, Al-heggami MA, Al-hag S. Identify and sensitivity 
to antifungal drugs of Candida species causing vaginitis isolated from vulvovaginal infected patients in Sana'a city. Der Pharma. Chemica. 2014; 6(1): 336-42.

11. Al-Hedaithy S. Spectrum and proteinase production of yeasts causing vaginitis in Saudi Arabian women. Med SciMonit., 2002; 8(7): 498-501.

12. Darce Bello M, Gonzalez A, BarnabeC, Larrouy G. First characterization of Candida albicans by Random amplified polymorphic DNA method in Nicaragua and comparison of the diagnosis methods for vaginal candidiasis in Nicaraguan women.

13. Holland J, Young M, Lee O, Lee S. Vulvovaginal carriage of yeasts other than Candida albicans species. Sex Transm Infect, 2003; 79: 249-250.

14. Pirotta M, Garland S. Genital Candida species detected in samples from women in Melbourne, Australia, before and after treatment with antibiotics. J ClinMicrobiol., 2006; 44(9): 3213-7.

15. Gultekin B, Yazici V, Aydin N. Distribution of Candida species in vaginal specimens and evaluation of CHROM agar Candida medium. Mikrobiyol Bul., 2005; 39(3): 319-24.

16. Pakshir K, Yazdani M, Kimiaghalam R. Etiology of vaginal candidiasis in Shiraz, Southern Iran. Res J Microbiol., 2007; 2: 696-700.

17. $\mathrm{Xu} \mathrm{Y,} \mathrm{Chen} \mathrm{L,} \mathrm{Li} \mathrm{C.} \mathrm{Susceptibility} \mathrm{of}$ clinical isolates of Candida species to fluconazole and detection of $C$. albicans ERG11 mutations. J Antimicrob Chemother., 2008; 61(4): 798-804.

18. Emmanuel N, Romeo O, Mebi A, Mark O, Scordino F, Bessy EI, et al., Genotyping and fluconazole susceptibility of Candida albicans strains from patients with vulvovaginal candidiasis in Jos, Nigeria. Asian Pacific J Tropical Dis 2012; 2012: 48-
50.

19. Babin D, Kotigadde, Rao Sunil P and Rao TV. Clinico-mycological profile of vaginal candidiasis in a tertiary care hospital in Kerala. International Journal of Research in Biological Sciences, 2013; 3(1): 55-59.

20. Kalia N, Singh J, Sharma S, Kamoj S, Arora $\mathrm{H}$ et al., Prevalence of Vulvovaginal Infections and species specific distribution of vulvovaginal candidiasis in married women of north India. Int. J. Current Microbiology and Applied Sciences 2015; 4(8): 253-266.

21. Mahnaz Mahmoudi Rad, Amenehsh Zafarghandi, Maryam Amel Zabihi, Mahkam Tavallaee, and Yasaman Mirdamadi. Identification of Candida Species Associated with Vulvovaginal Candidiasis by Multiplex PCR. Infectious Diseases in Obstetrics and Gynecology 2012.

22. Ibrahim Ali Altayyar, Alliwa Shiha Alsanosi and Nazar Abdalazeem Osman: Prevalence of vaginal candidiasis among pregnant women attending different gynecological clinic at South Libya; European Journal of Experimental Biology, 2016, 6(3): 2529)

23. ElFeky DS, Gohar NM, El-Seidi EA, Ezzat MM, AboElew SH. Species identification and antifungal susceptibility pattern of Candida isolates in cases of vulvovaginal candidiasis. Alexandria J Med. (2016), 52, 269-277.

24. Kalkana A, Guzel AB, Khalil I et al., Yeast vaginitis during pregnancy: L Susceptibility testing of 13 antifungal drugs and boric acid and detection of four virulence factors: Medical Mycology: 2012 (50); 585-593.

25. Jindal N, Gill P. An epidemiological study of VVC in women of child bearing age. Ind J Med Microbiol., 2007 
(25) 1:175-176.

26. Koga-Ito CY, Lyon JP, Vidotto V, Resende MA. Virulence factors and antifungal susceptibility of Candida albicans isolates from oral candidiosis patients and control individuals. Mycopathologia. 2006; 161:219-23.

27. Costa CR, XistoSena P, Lucia KH. Differences in exoenzyme production and adherence ability of Candida spp. isolates from catheter, blood and oral cavity. Rev. Inst. Med. Trop. Sao Paulo. 2010; 52(3):139-43.

28. Basu S, Gugnani HC, Joshi S\& Gupta N. Distribution of Candida species in different clinical sources in Delhi, India, and proteinase and phospholipase activity of Candida albicans isolates. Rev Iberoam Micol 2003; 20: 137-140.

29. Vivek KS, Deepali S, Archana S and Asha MJ. Prevalence of vaginal candidiasis in diabetic women of Madhya Pradesh, India. Int.J.Curr.Microbiol.App.Sci., (2015) 4(5): 834-846.

30. Suzane Katy RO, Dalia Cristine VA, Luiz Henrique BG et al., Prevalence and production of enzyme by candida isolates from vaginal secretion samples. Rev Patol Trop., vol 42(2):161-176.

31. Candido RC, Toloi RT, Franceschini SA, Garcia FR, Minto ECM. In vitro activity of antimycotic agents determined by E-test method against vaginal Candida species. Mycopathologia, 1998; 144: 15 - 20.

32. Samaranayake YH, Dassanayake RS, Jayatilake. Phospholipase B enzyme expression is not associated with other virulence attributes in Candida albicans isolates from patients with human immunodeficiency virus infection. $J$ Med Microbiol. 2005; 54: 583-93.

33. Fule SR, Das D, Fule RP. Detection of phospholipase activity of Candida albicans and non-albicans isolated from women of reproductive age with vulvovaginal candidiasis in rural area. Indian Journal of Medical Microbiology 2015; 33(1):92-95.

34. Mahmoudabadi Z, Zarrin M, Miry S. Phospholipase activity of Candida albicans isolated from vagina \& urine samples. Jandishapur J Microbiol 2010; 3:169-73.

35. Deorukhkar S, and Saini S. "Non albicans Candida species: its isolation pattern, species distribution, virulence factors and antifungal susceptibility profile," Intern J of Med Science and Public Health. 2013; vol. (2) 3 533-38.

36. Borst A, Fluit AC. High levels of hydrolytic enzymes secreted by Candida albicans isolates involved in respiratory Infections. J Med Microbiol. 2003; 52: 971-4.

37. Thamke DC, Tayade HA, Tayade SA et al., Biofilm formation among candida albicans isolated from vagina. IJBAR, 20(05): 12

38. Hawser SP and Douglas LJ. Resistance of Candida albicans biofilms to antifungal agents in vitro. Antimicrob. Agents Chemother. 39: 2128-2131.

39. Ilknur Dag, NuriKiraz and Yasemin OZ. Evaluation of different detection methods of biofilm formation in clinical Candida isolates. Afr. J. Microbiol. Res. 2010; 4(24): 27632768.

40. Tumbarello M, Posteraro B, Trecarichi EM. Biofilm Production by Candida Species and Inadequate Antifungal Therapy as Predictors of Mortality for Patients with Candidemia. Journal of Clinical Microbiology. 2007: 18431850.

41. Aurean D'Eca Junior, Anderson Franca Silva, Fernanda Costa Rosa. In vitro differential activity of phospholipases and acid proteinases of clinical isolates of Candida. Revista da Sociedade 
Brasileira de Medicina Tropical. 2011; 44(3): 334-338.

42. Kantarcioglu AS, Yucel A. Phospholipase and protease activities in clinical Candida isolates with reference to the sources of strains. Mycoses 2002; 45: 160-165.

43. Shimizu MT, Almeida NQ, Fantinato V, Unterkircher CS. Studies on hyaluronidase, chondroitin sulphatase, proteinase and phospholipase secreted by Candida species. Mycoses 1996; 39: 161-167.

44. Prasad R, Kapoor K. Multidrug resistance in yeast Candida. Int Rev Cytol. 2005; 242: 215-48.

45. Razzaghi-Abyaneh $\mathrm{M}$ et al., Species distribution and antifungal susceptibility of Candida spp. isolated from superficial candidiasis in outpatients in
Iran.JMycol Med, 2014 24(2): 43-50.

46. Vazquez JA, Arganoza MT, and Akins RA. Stable Phenotypic Resistance of Candida Species to Amphotericin B Conferred by Pre-exposure to Sub inhibitory Levels of Azoles. J. Clin. Microbiol.,1998, 36(9): 2690-95.

47. Wang $\mathrm{E}$ et al., The ever-evolving landscape of candidaemia in patients with acute leukaemia: non-susceptibility to caspofungin and multidrug resistance are associated with increased mortality. J Antimicrob Chemother., 2015.

48. Pfaller MA, DiekemaDJ. Azole antifungal drug cross-resistance: mechanisms, epidemiology, and clinical significance. J Invasive Fungal Infect 2007; $1: 74$.

\section{How to cite this article:}

Rafat Siddiqi, D.K. Mendiratta, Atul Rukadikar and Sandhya Gadre. 2017. Study of Virulence Markers and Antifungal Susceptibility by Vitek-2 in Various Candida Species Isolated from Cases of Vulvovaginal Candidiasis. Int.J.Curr.Microbiol.App.Sci. 6(12): 3593-3605. doi: https://doi.org/10.20546/ijcmas.2017.612.416 